\title{
Subjectivity in a context of environmental change: opening new dialogues in mental health research
}

Article

Accepted Version

da Cal Seixas, S. R. and Nunes, R. J. (2017) Subjectivity in a context of environmental change: opening new dialogues in mental health research. Subjectivity, 10 (3). pp. 294-312. ISSN 1755-635X doi: https://doi.org/10.1057/s41286-017-0032-z Available at https://centaur.reading.ac.uk/73246/

It is advisable to refer to the publisher's version if you intend to cite from the work. See Guidance on citing.

To link to this article DOI: http://dx.doi.org/10.1057/s41286-017-0032-z

Publisher: Springer

All outputs in CentAUR are protected by Intellectual Property Rights law, including copyright law. Copyright and IPR is retained by the creators or other copyright holders. Terms and conditions for use of this material are defined in the End User Agreement.

www.reading.ac.uk/centaur

\section{CentAUR}


Central Archive at the University of Reading

Reading's research outputs online 


\title{
Subjectivity in a context of environmental change: opening new dialogues in mental health research
}

\begin{abstract}
In a period of unstable experimentation with challenges of globalisation of associated risks, and disenchantment with 'enduring injustice', we bring forward a consideration of subjectivity to the study of environmental change and mental health. We begin by identifying how mainstream climate change and mental health studies are unable to explain the emergent and co-evolutionary pathways of agency. As a means of freeing these studies of their objective dimensions of linear-causation, we argue in favour of a repositioning of subjectivity within an appreciation of recognition conflicts and beyond the over-deterministic interpretations of power centres - state, market or religion-. We draw on one example of scientific research that was conducted in a region undergoing strong environmental, social and cultural changes, in the state of São Paulo / Brazil, with the aim to open mental health research to new dialogues, to which we contribute with the notion of the 'pluriversal subject'.
\end{abstract}

Key-words: subjectivity; environmental change; mental health; disenchantment; pluriversal 


\section{Introduction}

Studies correlating the impacts of extreme climatic events with mental health are among the most recent in the scientific literature. However, despite a significant increase in research on the effects of climate change on mental health, this area of study remains challenging and elusive as to its exact relationship of influence. Conclusive findings are difficult to generate with the variety of different methods that have been used to examine cases worldwide. Nevertheless, these findings are particularly important because of the implications they carry for urban and regional planning and development in areas of acute risk, especially for vulnerable and disenfranchised communities, as well as for public health care services.

More importantly, most mental health impact studies share the suggestion that extreme weather events should be treated as direct consequences of climate change. These studies predominantly establish linear-causal relationships between climate change and mental health impacts, which are often grounded in climate science, together with inputs from epidemiology. What remains unclear in our view, however, is the difference between the objective dimensions of these scientific claims on the mental health impacts of climate change and subjectivity, relating to the social construction or recognition of 'suffering' and the legitimacy of its associated drivers - as understood through individual and collective responses to it.

This clearly presents itself as a 'gap' in current scientific research, which requires the opening of a new dialogue on the relationship between climate change and mental health. These studies are unable to explain the emergent and co-evolutionary pathways of agency, of the multiple diverse ways in which the subjective and objective dimensions of climate change impact on mental health and subjective well-being. With this aim, we put forward the following question: In what way is it possible to contribute to an understanding of the relation of environmental change processes and their influences on the mental health of 
populations through a concept more comprehensive and effective, while listening to the affected? The concept of subjectivity plays a key role in this paper because it offers us new grounds for re-examining our understandings of mental health, from an interdisciplinary vantage point that goes beyond biological and climate sciences.

The strength of this approach, to which we understand that subjectivity is an adequate entry point, insofar as it allows a greater interdisciplinary comprehension of human complexity, offers us the ability to factor in different forms of human suffering and agency. In other words, we are drawn into studies of the social construction of subjectivity and the design and incorporation of its narratives into decision-making on an urban level and across public services. Taking recent debates over subjectivity into consideration, we further argue that this approach requires a focus on the idea of recognition that embodies subjectivity, in addition to an appreciation of the self-induced and socially constructed ideas of suffering, and individual and collective responses to that suffering or agency (McNay 2008). This becomes an organisational dilemma for urban policy where planning for health and well-being is faced with 'recognition conflicts' in the face of 'enduring injustice' (Spinner-Halev 2012; Malloy 2014). The same particularly holds true, we argue, at the level of the self in the form of 'psychic negotiations' - "an arrested, inchoate form of mourning [that] is at the heart of much of the inaction in response to ecological degradation" (Lertzman 2015, p. xiii; c.f. also Lertzman 2010a, 2010b). In other words, for the purposes of this paper, it is how we individually and collectively problematise health and well-being; it is how we respond and consequently construct identities to suit, and how places shape these outcomes.[SS1]

In line with this approach, the modern subject is one that embodies multiple, competing and contradicting subjectivities in a context of environmental change, where the universality of ideas of "sustainable development" (the 'ecological subject' - Floriani et al 2010), of "resilience" (the 'resilience subject' - Aranda et al 2012) can be both desired and undesired 
forms of practice (c.f. Agyeman et al (2003) on 'just sustainabilities'). It is in this appreciation of the pluralism and emergence of everyday responses of adaptation to environmental changes that we argue for a re-positioning of subjectivity, which can offer us a way out of, and into the complex inter-relationships of the objective and subjective dimensions of mental health research.

\section{Background and some definitions}

In the thought-provoking editorial by Page and Howard (2010), the authors ask: "Will mental health be discussed in Copenhagen after all?" In this article, the authors criticize the United Nations Climate Change meeting in Copenhagen in December 2009 for a scientific void. The gap is one where it is possible to observe a large number of studies on the relationship between climate change and their influences on human health (McMichael et al., 2006; McMichael and Martens, 2009; Smith and Desai, 2009; Harlan and Ruddell, 2011), while there is still a limited understanding of its impacts on mental health in particular (Lundberg, 1998; Srivastava, 2009; Berry et al., 2010).

The study of mental health is fundamental to the effective delivery of public health services, of individuals and the community, not only because of the value of these analyses themselves, but because mental health is a critical determinant of physical health (The Lancet, 2016). This understanding is directly grounded in recent attempts to include mental health indicators in the post-2015 Sustainable Development Goals (SDGs) for 2030, successor to the Millennium Development Goals (MDGs) of the United Nations (Thornicroft and Votruba 2016 Better Mental Health for All 2016).

Thornicroft and Votruba (2016) emphasize that this embeddedness of mental health into future sustainable development practices is an historic opportunity, and should be centred on global efforts to reduce mental illness, considering the role that such diseases represent for 
society globally, premature mortality, stigma and human rights violations, not to mention that most people with mental illness globally are not adequately treated. Nevertheless, studies correlating the impacts of extreme climatic events with mental health are the most recent to be found in the scientific literature. Some older reports have discussed natural disasters and their impact on health and psychological well-being, potentially due to extreme events having been categorized as natural disasters at the time (Crighton et al. 2003; Weisler et al. 2006; Morrissey and Reser 2007; Kessler et al. 2008; Madrid and Grant 2008). However, most of these studies suggest the impacts on mental health result from major external weather events as a direct consequence of climate change. These events can have serious implications and far-reaching consequences for mental health, especially for the most vulnerable social segments of societies. In turn, these studies call for further in-depth investigations in order to "avoid devastating consequences on the individual, the community and society in general" (Fritze et al. 2008, p. 1).

While these studies can play an important role in establishing the impacts on human health, we must recognise the limitations of their predominantly epidemiological approaches (Kreiger 2001), insofar as they are based exclusively on a cause and effect analysis and on quantitative data - leaving aside the more "daring" approaches that allow us to listen to those affected by mental illness (Blackman 2001, 2010 and 2012; Cromby and Harper 2009; Terkelsen 2009; Frosh 2016; and Liebert 2017). Thus, it is fundamental that we move beyond the limitations of these epidemiological approaches to consider that climate change can negatively influence mental health, but that the main problems of mental health can begin in childhood where major risk factors can be related to the family and the environment in which the child grows. These factors can be embodied in adolescence and triggered later in adult life, lending itself to an insecure family environment, with a predominance of abuse and violence, as well as serious and adverse events such as illness and death (The Lancet 2016). 
Altogether the environment in which people live, broadly speaking, includes the peri-family aspects that include adolescent upbringing, the objective and subjective conditions of life that are associated with socioeconomic aspects, working conditions, ecosystems and natural resources (Lundberg 1998; Pineo 2012; Thornicroft and Votruba 2016). But what should be factored into this wider environment - especially when we talk about change and stability in that environment? With the aim of this paper focused on bringing forward a consideration of subjectivity to the study of environmental change and mental health, it is imperative then that we clarify what we define as mental health and its influences.

\section{Definitions}

In order to better understand the "locus" of our argument in this paper, we begin by looking to O'Brien and Leichanko (2000). According to the authors, the contemporary world is undergoing a synergy of climate change and economic globalisation, two major global processes. In their opinion, both processes involve long-term changes, which will have different impacts around the world. They also argue that these two aspects, which they refer to as "double exposure" (p. 227), are usually not treated together. The term refers to the fact that certain regions, sectors, ecosystems and social groups can be confronted simultaneously by the impacts of climate change and the consequences of globalisation. In the remaining sections of this paper, we will refer to this "double exposure" as environmental change. It involves climate change, as well as alterations to ecosystems and regional infrastructures. It may cause damage to socioeconomic systems and human health, as well as affect the quality of life in various parts of the planet. Economically disadvantaged sectors of society are particularly vulnerable to it when they are subjected to more precarious urban environmental conditions (Turner et al. 1990; Patz et al. 2007; Tacoli 2009; Szersynski and Urry 2010; Kotir 2010; Jasanoff 2010; Min et al. 2011). 
When Page and Howard questioned the place of mental health in climate change debates at United Nations Climate Change meeting in Copenhagen in December 2009, they pointed to the indirect impacts of climate change (e.g. migration, urbanization and economic collapse) and its effects on the mental health of populations, especially those from developing or vulnerable regions (2010, p. 179). In this context of environmental change, we define mental health according to Berry et al. (2010). Berry et al provide a simple yet sophisticated definition of mental health as a dynamic and continuous situation, in which the individual has "the ability to think, feel, learn and socialize with their emotions and the reactions of others" (p. 124). In this statement, the authors stress that mental health problems differ for each individual in their causes, symptoms, effects and treatment options, but that all cases can be characterized by changes in mood, feelings, and behaviour. Usually, these problems present themselves as health conditions associated with distress, suffering and the disruption of psychological functions. Some mental problems (schizophrenia and other psychoses, bipolar disorder as well as some anxiety and personality disorders) are less common in society than others (e.g. depression and other mood disorders, some anxiety disorders, psychological distress, substance misuse and eating disorders, dementia and other forms of cognitive decline), but all of them may be severe and/or enduring (p. 124).

Taken further, we define the relationship between subjectivity and mental health in a context of environmental change along four aspects or assumptions (Fritze et al. 2008): (a) the direct impacts of climate change, such as extreme weather events will have important implications for mental health; (b) climate change has already promoted impacts on social, economic and environmental aspects of mental health, and the most serious consequences are felt by the most vulnerable communities and populations; (c) the understanding of long-term consequences, i.e. the socioeconomic and environmental challenges that arise from climate 
change, can be reflected in potentially re-occurring emotional problems and anxiety; and (d) understanding the implications of climate change is an important starting point in the development of precautionary measures against the individual and social risks to communities, facilitating the development of mitigation strategies and the design of effective public policies.

\section{Minding the gap between objective and subjective dimensions of mental health research}

There has been a strong attempt to understand the effects of environmental change on human health, which various regions of the world have experienced. In fact, the last decade has seen a concentration of studies on the relationship between climate and health, which form the scientific basis of ongoing international debates (McMichael 1993, 1997a and 1997b; McMichael and Haines 1997; McMichael et al. 2006; Ebi and Semenza 2008; Kjellstrom and Mercado 2008; Kovats and Akhtar 2008; Kjellstrom et al. 2009; Cardwell and Elliot 2013; Dutta and Chorsiya 2013; Ermert et al. 2013). Many of these studies discuss the diversity of current and future problems, which humanity must face as a result of environmental change processes, especially when they relate to climate change and its impact on human health (Few 2007; Zimmerman and Faris 2011; Ebi 2013; Semenza et al. 2013; Wolf and McGregor 2013; Yamana and Eltahir 2013; Lofty 2014). It has been illustrated in this scientific literature that extreme events (e.g. droughts, floods, heat / cold waves, storms, hurricanes, etc.) have affected the planet in various ways by causing economic and human losses, endangering the biodiversity, raising sea levels, as well as impacting agriculture, the generation of hydropower, and human health (Mendonça 2005; Ahern et al. 2005; Marengo and Valverde 2007; Fuchs et al. 2011; Oven et al. 2012; Abraham et al. 2013).

From this point of view, it can be easily concluded that environmental change, especially due to its "double exposure" character, should become the object of interdisciplinary mental 
health research. For example, research linking climate change and extreme events is part of a wider set of environmental change processes that can have a subsequent impact on mental health. Hajat et al (2002) examined this correlation between warm temperatures and the mortality rates of London area residents (UK) between January 1976 and December 1996. The analysis showed that mortality rates were not necessarily closely correlated to high temperatures, but to variations of temperature (Hajat et al. 2002, p. 367). Kovats et al (2004) also have confirmed mortality rates to be a result of hot weather and heat waves in similar epidemiological studies. However, the authors have pointed out that little remains known about any other effects beyond mortality rates. Also, their research on the correlation between medical emergency incidents and heat waves in London between April 1994 and March 2000 were not highly conclusive. They argue that some fatal cases may have occurred because patients had not previously sought help from health care services. More importantly, the authors highlight the importance of further research on recognising risks by both public health services and the patients themselves.

Among these studies on temperature and health is the report by Gupta and Murray (1992) who presented a ground-breaking analysis that combined data from two larger studies conducted by the World Health Organization-WHO. In this work, the authors highlighted the need for further investigation of the relationship between geographical and climatic variables and schizophrenia, which should be supplemented with already available information on the role of sociocultural factors for this morbidity. The limited findings from all of these studies point to the two important considerations of the long-term effects of environmental change on the mental health of populations, particularly those most susceptible to the traumatic consequences of adverse climatic events (Berry et al. 2010, p. 123). For Berry et al (2010) these aspects include: the direct (from acute and subacute climatic events) and the indirect (impacts of physical health, physical and/or social environment, and from adaptation and 
mitigation) effects on mental health (cf. also Fritze et al. 2008; and Shukla 2013). The authors also point to the role of health care systems in addressing and compensating for both of these direct and indirect effects on mental health (Berry et al. 2010, p. 128).

Following Berry et al (2010), we share the view that participatory engagement of different aspects of human subjectivity, through the perceptions and narratives of those involved, can play a fundamental role in guiding public health strategies beyond academic advance (Pidgeon and Fischhoff 2011; Thomas 2013; Corner et al. 2014). We develop this understanding further through the concept of subjectivity before identifying some challenges with its links to environmental change and mental health, and moving forward corresponding academic debates.

\section{Approaching the concept of subjectivity}

The concept of subjectivity plays a key role in this paper. By briefly outlining the need for a deeper interdisciplinary understanding of mental health, which goes beyond an exclusively biological dimension, we stress the subjective dimension of complex human-environmental processes of change and the individual and collective responses to it. Approaching the concept of subjectivity can offer us the means to better understand different forms of human suffering as the outcome of socially produced subjectivities. These subjectivities in all of its contradiction can have direct consequences for the recognition given to mental health and its links to environmental change narratives.

Guattarri (1990) offers an early defence of the concept of subjectivity, considering the gravity and urgency of current environmental problems - not to mention that climate change was not yet on the agenda of recognized ecological problems when this work was written. However, Guattarri does stress the importance of changes to the context of everyday cultures of practice 
or ways of life; that is, he draws attention to external interferences with the centre of human subjectivity - "be it social, animal, vegetable, cosmic" (p.7).

In this way, the concept of subjectivity is a powerful instance in our ability to understand the relationship of environmental change and mental health beyond particular disciplinary boundaries. In other words, in addition to the contributions of the abovementioned epidemiological studies, individuals and social groups continue to undergo the difficulties of everyday life and/or suffering regardless of their inclusion in diagnoses, pathologies and / or mental illnesses. For example, we infer from previous research on fishing communities in the North Coast of State of São Paulo/Brazil how such daily struggles have been sustained and communicated to future generations.

Historically, the importance of the concept of subjectivity has been expressed in several disciplines such as sociology, anthropology, psychology, geography, gender studies and feminism among others (Blackman et al. 2008). Moreover, "subjectivity has been an important concept for academic research, and for intervening in social and political life, since the 1960 s, [...] changing the terms of debate across many areas of the social sciences" (ibid., pp. 1-2).

We agree with Blackman et al (2008) and others on the complexity and historicity of the concept of subjectivity (c.f. Pulido-Martinez and Walkerdine 2007; Wetherell 2008; and Blackman 2014), and its roots in French philosophy - particularly in the structural Marxism of Althusser and in the Nietzschean influenced philosophy of Foucault (Burkitt 2008, p. 237). Yet in addition to many other theoretical and methodological contributions to the study of subjectivity, the dominant factor in all these approaches is that subjectivity remains a constituent and dynamic element of modern society (c.f., Souza Santos 1993, Maley 1994; Ortner 2007; Thrift 2008; Dunst and Edwards 2011; Schraube and Sørensen 2013). 
Moreover, while we do recognize the above ontological tradition of the concept of subjectivity, it is important to remind ourselves of the sociology of Weber (Weber, 1946, 1958) - where it is understood that science and religion shape the modern subject. Though, like Schiller before him in The Gods of Greece ([1788] 1851), Weber (ibid.) expresses his pessimism vision of modern life where the subject can experience a disenchantment with the world (c.f. also Greisman 1976). The future challenge for subjectivity studies, then, and for mental health research in particular, it is one where neither science nor religion allows the modern subject to understand or recognize her/is dilemmas in a more structured way through the use of its modes of perception, affection, thinking, wanting and fearing (Ortner 2007, p. 376).[SS2]

\section{Considering subjectivity in a state of disenchantment}

The subject in a state of disenchantment raises particular challenges for the concept of subjectivity in relation to recognitions of suffering. Our individual and collective responses to such risks (agency) would support the view that subjectivity can be considered a guiding heuristic for how people act in the world. For Ortner (2007), then, agency contains a strong component of subjectivity because it is made of desires and specific intentions, guided by feelings, thoughts, and meanings that are culturally determined (see also McNay 2008). In other words, actions are influenced and determined by the most complex constitution of the subjective being (Ortner 2007, p. 380).

The disenchanted subject, then, may lead us to think that mental suffering - for example, depression - can be considered as one of the expressions of the human tragedy, e.g. social complexity, social and environmental changes, wars, violence, scarcity of natural resources, unemployment, poor housing conditions, loss of social ties, and/or climate change at the level of individual consciousness and experience (Crighton et al. 2003; Fussel et al. 2006; Smith 
and Desai 2009; O’Brien 2010; Dodds 2011; Ebi 2013; Weintrobe 2013; Clayton et al. 2015 and Orange 2016). Like Schiller and Weber before us, we are again faced with an unprecedented crisis of meaning, in a state of disenchantment, which is reflected in the knowledge, perceptions, aspirations, memories, and feelings that must then guide us through an array of competing risk scenarios or recognition conflicts (Walkerdine 1985, 2007; Whitmarsh 2009; Tafarodi 2013).[ss3]

A similar situation can be found in times of rapid social, cultural, technological, and political change, where stability loses more and more importance. Here, daily life is restructured at the interface between local and global practices in everyday life (c.f. Pink 2012; Schatzki 2001, 1991), leaving individuals to make choices from an increasingly diverse range of options. These options may be related to inherent cultural aspects in place, but also to consumerism and everyday decisions, which go beyond tradition, religion and traditional family cultures (Inglehart 1997; Lash 1997).

So does the modern subject, since it no longer has to resort to neither religion nor science, express its suffering or disenchantment through depression and consequently undertakes a constant search for palliative cures (e.g. drugs) to silence its desire and pain? This question places subjectivity within an appreciation of recognition conflicts (Malloy 2014). Güell (2002, p. 2) for example asks, what good does development serve, if real people and their social ties disappear from the horizon, marked by all the challenges they face? Naturally, this observation is not shared unanimously. Economists, for example, put forward another question: What is the benefit for the economy and politics to take the wishes, identities, languages, fears and memories of individuals and communities into account (Güell 2002, p. 2)?

Gill (2008), in her study on cultural representations of the discourse on post-feminism, shows the challenging discussion that is also ours when she asks crucial questions about 
subjectivity. As we know almost nothing about the social and cultural internal actions of the subject, the very language impoverishes academic dialogue when it imposes restrictions between what is inside and outside of the individual. To counter the logics of monodisciplinary exclusivity, then, we need to first recognize the role and deployment of an interdisciplinary understanding of the subject as one of emergence and co-evolution, of 'becoming' (Nancy 2000). Leff and Elizalde (2010, p.7) point out, for instance, that the modern subject is - thanks to its consciousness - open to the notion of a collective being, which is formed in conjunction with a configuration of emerging environmental rights, where the subjects and their subjectivities will (re)define new identities, and reconfigure the arrangement of new social actors in the drive toward a more just world.

In other words, the modern subject must not be confused with notions that reduce "community" to a shared positive essence, for example - a unity who, when faced with the unfair or disproportionate effects of environmental changes, must not be addressed through universal ideals of justice or apriori notions like sustainable development or resilience. We see such universal ideals in the notion of "sustainable development" through the "ecological subject' (Floriani et al. 2010). The 'ecological subject', according to Floriani et al (2010, p. 81 ), is the means to act decisively in the construction of a model of development that will not only prioritize economic aspects, but also human and environmental ones. The ecological subject recognizes apriori that natural resources and social policies are key to a "sustainable development" equation. Aranda et al's 'resilience subject' (2012) presents a similar framing of the universal in the ideal of "resilience".

Our position, however, breaks with such apriori points of departure. From reading Walkerdine $(1985 ; 2007)$ and Stengers $(2008)$, the negotiation and compromise of multiple individual and collective subjectivities around mental health and environmental change, of the different ways of expressing human suffering through fear, anxiety, alienation, and in the 
different ways that suffering is lived, affects daily life, and is socially represented and communicated merits further investigation (see also Pulido-Martinez and Walkerdine, 2007). Thus, with particular consideration of the need to redress subjectivity in a state of disenchantment, of 'enduring injustice' (Spinner-Halev 2012), we draw inspiration from Amartya Sen, who convincingly argues in The Idea of Justice (2011) for a notion of the universal as always plural - as pluriversal. So in the light of our abovementioned consideration, there is a need to rethink subjectivity and, in turn, that of the subject.

Underlining this approach is essentially a Weberian account where, as far as future studies of subjectivity are concerned, we argue that there can be multiple subjectivities co-placed in the subject; that is, there can be multiple ways or practices through which the subject reasons pragmatically in a context of enduring injustice. While maintaining the Weberian tradition of anti-positivist social inquiry, of the potential for multiple causalities, we also expand this tradition into the complementary realm of psychoanalytic approaches. That is, beyond the traditional Weberian forces of religion and state on our modes of perception, affection or wanting, the 'pluriversal subject', we propose, arrives at choices from an increasingly diverse range of options that can be understood as a (re)bundling of practices (Schatzki 2001, 1991). Following Lertzman (2015), these pragmatic choices are the product of everyday 'psychic negotiations' in a state of disenchantment that lends itself to emergent or co-evolutionary cultures of practice (Guattari 1990). In the following section, we provide a case example where the challenges of redressing subjectivity in a state of disenchantment are discussed.[SS4]

\section{Establishing some links between environmental change, mental health, and subjectivity}

The first author of this paper carried out the scientific research below. It includes a study of fishing communities in the densely populated municipality of Caraguatatuba - situated in the North Coast region of the State of São Paulo during the last decade (Seixas et al. 2016; 
Seixas et al. 2014; Seixas et al. 2012). This study was conducted in a geographical area that has undergone significant environmental change over a short time span, degrading the physical and mental health of individual community members with direct impacts on their subjective well-being and quality of life.

The municipality of Caraguatatuba has been the subject of extensive environmental, demographic, urban and economic change through the development of large-scale industrial projects (oil and gas), the expansion of transport systems (e.g. ports and access roads), and a marked increase in mass tourism (Seixas et al. 2014). It is an example of intensified environmental change, which has disrupted regional economic activities directly and indirectly - especially those related to fishing and aquacultures (Seixas et al. 2014; Seixas et al. 2012). This research charts the environmental changes that have occurred in the region in recent decades with a focus on the perceptions of environmental change by residents. For the purposes of this paper in particular, we have set out to re-examine the production of subjectivities in individual fishermen in the community around his/er experience of environmental change and its perceived associations to mental health.

The methodological approach to the original research involved: (1) a direct observation of everyday living in the community (fishing); (2) interviews with a selected sample of individuals, with particular consideration for their proximity to, and reliance on natural resources for both their social and economic livelihoods. These narrative interviews were designed to capture the experience of environmental change in this community, with the aim to reconstruct individual and collective subjectivities and its relations to place-attachment and identity; (3) the collection of socio-environmental, economic and demographic data; and (4) follow-up interviews with mental health care professionals, who attend to this region, for their collective institutional responses and recognition of the health problem(s) and its 
drivers, as well as to better understand the individual recognition of ill-mental health across the community.

Interviews with the fishing community of Cocanha Beach (Caraguatatuba) suggested that the interviewees were aware of the ongoing processes of environmental change (i.e., climatic variations, and changes to sea water temperature, and water quality), which were affecting fishing stocks and, in turn, impacting on all related economic activities (Seixas et al, 2012; Seixas et al, 2014). The interviewees recounted changes to their daily lives - both in the physical landscape and in their use of the region's resources, which has altered their fishing practices and associated social and economic livelihoods (Seixas et al, 2014). For the interviewees, the most significant change was the decrease in fish stocks when compared to the abundance of stocks in the past. It was the starting point for all changes to their daily lives, including the cultural aspects of their practices as artisanal fishermen. In their testimonies, the reduction in fish stocks was evident when compared to the previous two to three decades (interviewed 3 and 8, 2011), despite significant decreases in household consumption of fish (interviewed 7, 2011).

'Corvina', 'cação' and 'bagre', which are among of the most common species on the coast of São Paulo (Seixas et al. 2012), was used to contextualize the decrease of fish stocks in the recent years. However, it was common practice to fish nobler fish such as 'bonito' and 'dourado' (Interviewed 3, 2011). As a consequence of the reduction in fish stocks, a greater effort on the part of the fishermen can be observed in their efforts to sustain household diets and livelihoods with fishing. This research identified the physical effort consequently undertaken by the individual fisherman, including the need for more trips further out to sea, and the sheer financial cost of it all. This greater human and financial investment contributed to, in their view, a rapid deterioration in health. For instance, many fishermen mentioned the 
physical stresses that transpired such as muscular pains and the consequential limited mobility that prevented them from fishing altogether (interviewed 5, 2011).

As a result of the reduction of fish stocks, artisanal fishing practices transferred from a primary to a secondary activity that complemented the interviewees' household income. Currently, few are living exclusively from artisanal fishing, and among those interviewed, it is common to develop additional streams of income while maintaining fishing as a leisure or hobby activity (interviewed 2, 5 and 7, 2011). Nevertheless, in some cases, the resultant unemployment and the socioeconomic disadvantages negatively impacted on the mental health of those unable to adapt. This exposed some fishermen to greater psychosocial risk factors such as self-perceived negativity, stress, insecurity, loss of personal autonomy and social isolation (Patel et al. 1999; Shields and Price 2001; Fritze et al. 2008).

Moreover, climate change is likely to bring impacts on mental health and well-being through its impacts on economic systems, costs of living, and on the unequal distribution of these impacts among members of a community (Fritze et al. 2008). In fact, its effects will be disproportionately felt by already vulnerable individuals, including those with low incomes, and communities directly dependent on their local environment for survival - as in the region studied (Lee 2007). Thus when we analyzed the data from the Brazilian Health System in relation to the mental health of the residents of the municipalities of the North Coast of São Paulo, especially the hospital admissions between 2000 and 2010, there was an unsurprisingly higher than the average rate in Caraguatatuba when compared to the average for state of São Paulo. Interviews with health care professionals further showed that in the same period, from the patients who sought help from mental health services in the municipality, 60\% were diagnosed with depression (Seixas et al., 2012; Seixas et al., 2014; Seixas et al, 2016). 
The effects of these environmental changes on the social and economic livelihoods of these artisanal fishermen cumulatively spun a complex web of emotional responses. Despite their adaptation, their struggles remain alive in their memories of past and reoccurring environmental changes, in the artisanal fishing practices that have been sustained albeit a complementary economic activity, and in the vestiges of a past economic mainstay that remains evident in the many boats, sheds and netting. The embodiment of this past by the interviewees, of their related sense of social, economic and physical stress, insecurity and helplessness, was also evident in their bitterness toward the future. In the face of the many difficulties they encountered, many fishermen did not support the maintenance of the activity for future generations, and often encouraged their offspring to migrate and seek other employment opportunities (interviewed 6, 2011).

What can be concluded from this research? We find that there is indeed something decisively obvious about this research when it is understood from the perspective of apriori notions of some universal ideal model of development - "sustainable", "resilient". That is, there is the risk that over-deterministic approaches are taken when inferring the role of the state, market and religion in these processes of environmental change and its 'enduring injustice', which we can deduce from the above case study research. The sense of despair and disenchantment among interviewee fishermen positions them in a context of conflicting recognitions of, psychic negotiations over the processes of environmental change and their role in it.

To put this into some perspective, we need only to note the interviewees' internal conflicts with the meaning that the practice of fishing holds for individual fisherman and their community at large. How individual fisherman will continue to trade-off and 'bundle' multiple everyday decisions, practices (Schatzki 1991, 2001), or identities in the face of climate science, we argue, calls for new dialogues in mental health research, which embraces the pluralism of individual and collective practices. More importantly, and to the root of our 
argument for this paper, epidemiological studies are consequently contingent, fractured and partial in a context of recognition conflicts over environmental change processes.

\section{Opening new dialogues in mental health research}

The link between processes of environmental change and its effect on mental health, albeit patchy and underexplored, has been approached through the lens of subjectivity. Particular consideration for the contemporary social context of disenchantment has been put forward as part of a re-positioning of subjectivity within an appreciation of recognition conflicts. The 'self', as a coherent set of individual subjectivities, as a subject to be understood and correlated with external processes of environmental change, gives way to the multiple associations and desires of the pluriversal subject. This view repositions the notion of subjectivity as a creative expression or symptom of environmental change evident in the adaptations of individual fisherman in Caraguatatuba, including but not limited to their selfperceived negativity, stress, and loss of personal autonomy; this stands in stark contrast to conventional liner-causal relationships.

In turn, we propose an approach to subjectivity in mental health research that is historically produced through a deep and dialectical place-based relationship between individuals and societies, and natures. Thus minding the gap between objective and subjective dimensions of mental health research, which shapes the pluriversal subject in the face of a disenchantment with enduring injustices, only gains meaning through the relationship that any one individual establishes by coping pragmatically with their problems under particular circumstances, i.e. how they feel, absorb, internalise, and express their problems in multiple ways. This gap is evident in the co-placement of multiple subjectivities in the subject, which can become in that instance reflective, deliberative, datable, and localized - even self-contradicting. It is thus a product of society, in so far as individual and collective recognition has been exercised 
socially, historically and politically (Guattari 1990; Kleinman et al. 1997; Melman 2003;

Bauman 2005; Gunaratnam 2014), and can therefore transform social points of view (Güell 2001; Gill 2008; Burkitt 2008) and contribute to a new social emancipatory politics (Dunst and Edwards 2011; Lertzman 2015; Orange 2016).[[SS5]

\section{Some concluding considerations}

Environmental change, as the synergy between planetary urbanisation and climate change processes, has become a topic of increasing relevance in recent years. These processes already promote, intensify, and affect regional economic activities directly and indirectly, especially those related to fishing and aquacultures, as well as agriculture. This often results in social, economic, cultural and subjective consequences, from which we argue that an understanding of mental health emerges in relation to processes of environmental change. In this paper, we have begun with the challenge of assessing the relationship of mental health to processes of environmental change. We have observed that most of the examined studies have dealt with the effects of temperature and major external events (e.g. droughts, floods, cyclones and storms) on physical and mental health, and the subsequent problems they instigate (e.g. the degradation of ecosystems services and the eradication of livelihoods). Most studies have examined social groups that have suffered directly from the traumas caused by such events, with particular consideration for the degree of vulnerability to which these social groups are exposed. While we recognize the theoretical and methodological importance of these oftentimes-epidemiological studies, we set out to free them of their objective dimensions of linear-causal relationships. Our approach to subjectivity in mental health research is therefore broadly understood as the ability of individuals to deal with their everyday problems. This ability can be related to social, economic, environmental, cultural, and individual aspects. 
Our repositioning of the subject in the study of subjectivity, then, opens new dialogues in mental health research. We would suggest this is ultimately a new political project - where the production of subjectivity is the outcome of negotiated ideals and compromise where we embrace the fact that orientating practices of sustainable development and resilience can be undesirable in face of 'enduring injustice' (Spinner-Halev 2012), and where the universal ideas of justice are always plural (Sen 2011). Furthermore, it is through this appreciation of what we term the 'pluriversal subject' that we are able to more fully embrace the multiple ways or practices through which the subject reasons with injustices, which we have been able to infer from a re-examination of previous research on the fishing community of Cocanha Beach (Caraguatatuba). The pluriversal subject, then, does not work from a universal understanding of justice practically. Rather, we argue that the observed subjectivities of individual fisherman can be understood as a set of 'recognition conflicts' or 'psychic negotiations' over their self-worth, their sense of identity and place-attachment, and how they consequently construct new identities and/or subjectivities and communicate them to their offspring, for example (c.f. Lertzman 2015, p. xiii and Malloy 2014). This embrace of the psychoanalytic approach is layered onto our Weberian account - not in the absence of Weber.

The future challenge for subjectivity studies, then, and for environmental change and mental health research in particular, lies in a re-engagement of the subject in a state of disenchantment and 'enduring injustice' (Spinner-Halev, J. 2012). The pluriversal subject, we have argued, offers a way out of the universal ideas of justice where multiple subjectivities can be co-placed in the subject. The pluriversal subject is therefore understood through a means of social inquiry into the multiple everyday practices through which it reasons with enduring injustices pragmatically. In this regard the subject harbours multiple and oftentimes contradicting subjectivities and identities. This re-positioning of the subject is one of 
perpetual creative tensions; it is in this embrace of the subject as always plural, as one of

'becoming', of emergence and co-evolution with others that can fundamentally reshape the

study of subjectivity.[ss6]

\section{References}

Abraham, J.P., Baringer, M., Bindoff, N.L., Boyer, T., Cheng, L.J., Church, J.A., Conroy, J.L., Domingues, C.M., Fasull, J.T., Gilson, J., Goni, G., Good, S.A., Gorman, J. M., Gouretski, V., Ishii, M., Johnson, G.C., Kizu, S., Lyman, J.M., Macdonald, A. M., Minkowycz, W.J., Moffitt, S.E., Palmer, M.D., Piola, A.R., Reseghetti, F., Schuckmann, K., Trenberth, K.E. and Velicogna, I. (2013) A review of global ocean temperature observations: Implications for ocean heat content estimates and climate change, Review of Geophysics - American Geophysical Union, doi: 10.1002/rog.20022.

Agyeman, J., Bullard, R., and Evans, B (eds) (2003) Just Sustainabilities: Development in an Unequal World_(MIT Press).

Ahern, M., Kovats, R.S., Wilkinson, P., Few, R. and Matthies, F. (2005) Global Health Impacts of Floods: Epidemiologic Evidence. Epidemiologic Reviews 27, doi: 10.1093/epirev/mxi004

Aranda, K., Zeeman, L. and Scholes, J. (2012) The resilient subject: Exploring subjectivity, identity and the body in narratives of resilience. Health 16 (5):548-63, doi: $10.1177 / 1363459312438564$

Bauman, Z. (2005) Vidas desperdiçadas. Rio de Janeiro: Zahar.

Berry, H.L., Bowen, K. and Kjellstrom, T. (2010) Climate change and mental health: a causal pathways framework. Int J Public Health 55(2):123-32, doi: 10.1007/s00038-009-0112-0.

Better Mental Health for All: A Public Health Approach to Mental Health Improvement. (2016). London, Faculty of Public Health and Mental Health Foundation.

Blackman, L, (2014) Affect and automaticy: Towards an analytics of experimentation. Subjectivity 7, 362-384. doi:10.1057/sub.2014.19

Blackman, L. (2001). Hearing Voices: embodiment and experience. London: Free Association Books.

Blackman, L. (2010) Embodying affect: Voice-hearing, telepathy, suggestion and modelling the non-conscious. Body \& Society 16(1): 163-192. doi:10.1177/1357034X09354356

Blackman, L. (2012). Immaterial bodies: Affect, embodiment, mediation. London: SAGE

Blackman, L., Cromby, J., Hook, D., Papadopoulos, D. and Walkerdine, V. (2008) Creating subjectivities (Editorial). Subjectivity 22: 1 - 27. doi:10.1057/sub.2008.8

Burkitt, I (2008) Subjectivity, self and Everyday life in contemporary capitalism. Subjectivity 23, 236-245. doi:10.1057/sub.2008.13 
Cardwell, F S and Elliott, S J. (2013) Making the links: do we connect climate change with health? A qualitative case study from Canada. BMC Public Health 13:208, http://www.biomedcentral.com/1471-2458/13/208

Clayton, S; Wright, P D; Stern, P C; Whitmarsh, L; Carrico, A; Steg, L; Swim, J; and Bonnes, M (2015) Psychological research and global climate change. Nature Climate Change 5, 640-646, doi:10.1038/nclimate2622

Corner, A; Markowitz, E and Pidgeon, N (2014). Public engagement with climate change: the role of human values. WIRES Clim Change. doi: 10.1002/wcc.269

Crighton, E.J, Elliott, S.J; van der Meerc, J, Small, I, and Upshur, R. (2003) Impacts of an environmental disaster on psychosocial health and well-being in Karakalpakstan. Social Science \& Medicine 56: 551-567

Cromby, J., and Harper D.( 2009) Paranoia: A social account. Theory \& Psychology 19(3): 335-361. doi:10.1177/0959354309104158

\section{Dodds, J (2011) Psychoanalysis and Ecology at the Edge of Chaos: Complexity Theory,} Deleuze/Guattari and Psychoanalysis for a Climate in Crisis. UK: Routledge.[S57]

Dunst, A. and Edwards, C. (2011) Collective subjects, emancipatory cultures and political transformation. Subjectivity 4:1-8. doi:10.1057/sub.2010.29

Dutta, P. and Chorsiya, V. (2013) Scenario of Climate Change And Human Health In India. International Journal of Innovative Research \& Development 2(8): 157- 160.

Ebi, K L; Semenza, J C. (2008). Community-Based Adaptation to the Health Impacts of Climate Change. Am J Prev Med 35(5) 0749-3797

Ebi, K.L. (2013). Is Climate change affecting human health? Environemtal Research Letters 8(3): 31002-31004, doi: 10.1088/1748-9326/8/3/031002

Ermert, V., Fink, A.H. and Paeth, H. (2013) The potential effects of climate change on malaria transmission in Africa using bias-corrected regionalized climate projections and a simple malaria seasonality model, Climatic Change 120:741-754, doi: 10.1007/s10584013-0851-z

Few, R (2007) Health and climatic hazards: Framing social research on vulnerability, response and adaption. Global Environmental Change 17: 281-295.

Floriani, D., Ferreira, J. J. N. and Sousa, M. S. L. (2010) Para pensar a 'subjetividade' no debate do sócio-ambientalismo. Polis 9(27): 81-108.

Fritze, J.G., Blashki, G.A., Burke, S., and Wiseman, J. (2008) Hope, despair and transformation: Climate change and the promotion of mental health and wellbeing. International Journal of Mental Health Systems 2 (13), doi:10.1186/1752-4458-2-13

Frosh, S. (2016) Relationality in a time of surveillance: narcissism, melancholia, paranoia. Subjectivity 9(1): 1-16. doi:10.1057/sub.2015.19

Fuchs, R., Conran, M. and Louis, E. (2011) Climate change and Asia's coastal urban cities. Can they meet the challenge? Environment and Urbanization Asia 2 (1): 13-28.

Fussel, H-M, Kelin, R J T, Ebi, K L (2006). Adaptation, assessment for public health. In: Menne, B and Ebi, K L (eds). Climate change and adaptations strategies for human health. Germany: Steinkopff, Verlag, Darmstadt/WHO/Springer. 
Gill, R. (2008) Culture and Subjectivity in Neoliberal and Postfeminist times. Subjectivity 25: 432-445, doi:10.1057/sub.2008.28

Greisman, H. C. (1976) Disenchantment of the World: Romanticism, Aesthetics and Sociological Theory. The British Journal of Sociology 27 (4 ): 495-507.

Guattarri, F (1990) As três ecologias. Campinas: Papirus, ISBN 85-308-0106-7

Güell, P. (2002) Subjetividad social: desafío para Nuevo siglo. Polis 2, doi: $10.4000 /$ polis. 7853 .

Gunaratnam, Y (2014). Morbid mixtures: Hybridity, pain and transnational dying. Subjectivity 7, 74-91. doi:10.1057/sub.2013.21

Gupta, S. and Murray, R.M. (1992) The Relationship of Environmental Temperature to the Incidence and Outcome of Schizophrenia. The British Journal of Psychiatry 160: 788 792.

Hajat, S.,Kovats, R S., Atkinson, R W; Haines A. (2002) Impact of hot temperatures on death in London: a time series approach. Epidemiol Community Health 56, 367-372

Harlan, S L and Ruddell, D M. (2011) Climate change and health in cities: impacts of heat and air pollution and potential co-benefits from mitigation and adaptation. Current Opinion in Environmental Sustainability 3:126-134

Inglehart, R. (1997) Modernization and Postmodernization. New Jersey: Princeton University Press.

Jasanoff, S. (2010) A new Climate for Society. Theory, Culture \& Society 27(2-3): 233-253, doi:10.1177/0263276409361497

Kessler, R.C., Galea, S., Gruber, M.J., Sampson, N.A., Ursano, R.J. and Wessely, S. (2008) Trends in mental illness and suicidality after Hurricane Katrina. Molecular Psychiatry 13: 374-384. doi:10.1038/sj.mp.4002119

Kjellstrom, T. and Mercado, S. (2008) Towards action on social determinants for health equity in urban settings. Environment and Urbanization 20: 551-574, doi: $10.1177 / 0956247808096128$

Kjellstrom, T., Holmer, I. and Lemke, B. (2009) Workplace heat stress, health and productivity: an increasing challenge for low and middle-income countries during climate change. Global Health Action, doi: 10.3402/gha.v2i0.2047

Kleinman, A., Das, V. and Lock, M. (1997) Social Suffering. California: University of California Press.

Kotir, J. H. (2010) Climate change and variability in Sub-Saharan Africa: a review of current and future trends and impacts on agriculture and food security. Environmental Development Sustainability 3: 587-605.

Kovats, R. S and Akhtar, R. (2008) Climate, climate change and human health in Asian cities. Environment and Urbanization 20: 165 - 175, doi: 10.1177/0956247808089154

Kovats, R. S., Hajat, S; and Wilkinson, P. (2004) Contrasting patterns of mortality and hospital admissions during hot weather and heat waves in Greater London, UK. Оссир Environ Med 61: 893-898, doi: 10.1136/oem.2003.012047.

Krieger, N (2001) A glossary for social epidemiology. J Epidemiol Community Health 55: 693-700 
Lash, S. (1997) A reflexividade e seus duplos: estrutura, estética, comunidade. In: Beck, U, Giddens, A \& Lash, S. Modernização Reflexiva: política, tradição e estética na nova ordem social moderna. São Paulo: Unesp.

Lee, J. (2007) Climate Change and Equity in Victoria: Social Impacts of Climate Change on Low-income Earners. Friends of the Earth, Melbourne.

Leff, E. and Elizalde, A. (2010) Sujeto, subjetividad, identidade y sustentabilidad (Prólogo). Polis 9 (27): 7-12.

Lertzman $_{2}$ R (2015) Environmental Melancholia: Psychoanalytic dimensions of engagement (Psychoanalytic Explorations). UK: Routledge

Lertzman, R. (2010a) The myth of apathy: Psychosocial dimensions of environmental degradation. Unpublished PhD thesis, Cardiff School of Social Sciences, Cardiff University, UK.

Lertzman, R. (2010b) Psychoanalysis, culture, society and our biotic relations: Introducing an ongoing theme on environment and sustainability. Psychoanalysis, Culture \& Society 15, 113-116. doi:10.1057/pcs.2010.10[SS8]

Liebert, R.J. (2017) Beside-the-mind: an unsettling, reparative reading of paranoia. Subjectivity 1-23. doi:10.1057/s41286-016-0015-5

Lotfy, W. M. (2014) Climate change and epidemiology of human parasitosis in Egypt: Review. Journal of Advanced Research (2014) 5, 607-613 Madrid, P A. and Grant, R (2008). Meeting mental health needs following a natural disaster: Lessons from Hurricane Katrina. Professional Psychology: Research and Practice 39(1): 86-92.

Lundberg, A (1998). Environmental change and human health. In: Lundberg, A (ed). (1998). The environment and mental health. A guide for cliniciains. New Jersey, Lawrence E A, Publishers: 5-24.

Madrid, P A. and Grant, R. (2008) Meeting mental health needs following a natural disaster: Lessons from Hurricane Katrina. Professional Psychology: Research and Practice, 39(1): 86-92. DOI: 10.1037/0735-7028.39.1.86

Maley, T. (1994) The politics of time: subjectivity and modernity in Max Weber. In: Horowitz, A and Maley, T (eds). The Barbarism of reason: Max Weber and the twilight of enlightenment Toronto: University of Toronto Press.

Malloy, T. (2014) Reconceiving Recognition: Towards a Cumulative Politics of Recognition. Journal of Political Philosophy, 22(4), pp.416-437.

Marengo, J. A. and Valverde, M. C. (2007) Caracterização do clima no Século XX e Cenário de Mudanças de clima para o Brasil no Século XXI usando os modelos do IPCC-AR4. Multiciência 8: 5-28.

McMichael A.J. (1993) Planetary overload: global environmental change and the health of the human species. Cambridge: Cambridge University Press.

McMichael, A J and Martens, P (2009). Global environmental changes: anticipating and assessing risks to health In Martens, P and McMichael, A J (editors). Environmental Change, Climate and Health. Issues and research methods. Cambridge, Cambridge Universtity Press: 1-17.

McMichael, A. and Haines, A. (1997) Global climate change: the potential effects on health. BMJ 315 (27): 805-809. 
McMichael, A. J. (1997b) Integrated assessment of potential health, impacts of global environmental change: Prospects and limitations. Environmental Modeling \& Assessment 10 (2-3): 129-137.

McMichael, A., Woodruff, R. and Hales, S. (2006) Climate change and human health: present and future risks. The Lancet 367(9513): 859-869.

McMichael, A.J. (1997a) Global Environmental Change and Human Health. Ecosystem Health 3: 200-210, doi:10.1111/j.1526-0992.1997.00053.pp.x.

McNay, L. (2008) The Trouble with Recognition: Subjectivity, Suffering, and Agency. Sociological Theory 26(3): $271-296$.

Melman, C. (2003) O Homem sem Gravidade. Gozar a qualquer preço. (Entrevistas por Jean-Pierre Lebrun). Rio de Janeiro: Companhia de Freud.

Mendonça, F. (2005) Clima, tropicalidade e saúde: uma perspectiva a partir da intensificação do aquecimento global', Revista Brasileira de Climatologia 1(1): 100-112.

Min, S. K., Zhang, X., Zwiers, F. W., and Hegerl, G. (2011) Human contribution to more intense precipitation extremes. Nature 470: 378-381, doi: 10.1038/nature09763

Morrissey, S.A. and Reser, J. P. (2007) Natural disasters, climate change and mental health considerations for rural Australia. Aust. J. Rural Health 15: 120-125.

Nancy, J.-L. (2000) Being Singular Plural. Trans. R. D. Richardson and A. E. O’Bryne. Stanford, Calif.: Stanford University Press

O'Brien, K. (2010). Responding to environmental change: A new age for human geography? Progress in Human Geography, 35(4) 542-549, doi: 10.1177/0309132510377573

O'Brien, K.L. and Leichenko R.M. (2000) Double exposure: assessing the impacts of climate change within the context of economic globalization. Global Environmental Change 10, $221-232$

Orange, D. M. (2016) Climate Crisis, Psychoanalysis, and Radical Ethics. UK:

Routledge[sS9]

Ortner, S.B. (2007) Subjetividade e Critica Cultural. Horizontes Antropológicos 13(28): 375405

Oven, K.J., Curtis, S.E., Reanet, S., Riva, M., Stewart, M.G., Ohlemüller, R., Dunn, C.E., Nodwell, S., Domonelli, L. and Holden, R. (2012) Climate change and health and social care: defining future hazard, vulnerability and risk for infrastructure systems supporting older people's health care in England', Applied Geography 33: 16-24.

Page, L.A and Howard, L.M. (2010) The impact of climate change on mental health (but will mental health be discussed at Copenhagen?). Psychological Medicine 40(02):177 180, doi: $10.1017 / \mathrm{S} 0033291709992169$.

Patel V, Araya R, Lima M, Ludermir A, Todd C, Centre S, Porvorim A. (1999) Women, Poverty and Common Mental Disorders in Four Restructuring Societies. Social Science \& Medicine:49: 1461-1471.

Patz, A.J; Gibbs, H.K.; Foley, J.A.; Rogers, J. V.; Smith, K. R. (2007). Climate change and global health: quantifying a growing ethical crisis', EcoHealth, 4(4): 397-405.

Pidgeon, N. F. and Fischhoff, B. (2011). The role of social and decision sciences in communicating uncertain climate risks. Nature Climate Change 1:35-41 doi:10.1038/nclimate1080 
Pineo, H. (2012). Health and the built environment. The Lancet 380 (9848): 1146-1147, DOI: http://dx.doi.org/10.1016/S0140-6736(12)61665-1

Pink, S. (2012) Situating everyday life: Practices and places. Sage Publications.

Pulido-Martinez, H C and Walkerdine, V. (2007) Psychology, the world of work and subjectivity: Valerie Walkerdine Talks to Hernán C. Pulido-Martínez . Universitas Psychologica. Bogotá (Colombia) 6 (1): 185-194.

Schatzki, T. R. (1991) Spatial ontology and explanation. Annals of the Association of American Geographers, 81(4), 650-670.

Schatzki, T. R. (2001) Space, body and self. Annals of the Association of American Geographers 91(4), 698-702.

Schiller, F., 1851. The Poems of Schiller, Complete: Including All His Early Suppressed Pieces. Parker.[Ss10]

Schraube, E. and Sørensen, E. (2013) Exploring sociomaterial mediations of human subjectivity. Subjectivity 6,1-11, doi:10.1057/sub.2012.30.

Seixas, S. R. C., Höeffel, J. L. M., Botterill, T. D., Vianna, P.V.C. and Renk, M. (2014) Violence, tourism, crime and subjective mental health: opening new lines of research. In: Andrews, H. Tourism and Violence. Farnham, UK: Ashgate. 145-164.

Seixas, S.R.C., Renk, M., Höeffel, J. L. M., Conceicao, A.L. and Asmus, G. F. (2012) Global Environmental Changes and Impacts on Fishing Activities in the Northern Coast of São Paulo, Brazil. Urban Areas and Global Climate Change. Research in Urban Sociology12: 299-317, doi:10.1108/S1047-0042(2012)0000012015.

Seixas, SRC; Hoeffel, J L M; Renk, M; Asmus, G F. and Lima, F B. (2016). Weather Variability and Climate Change Impacts on the Mental Health of a Seaside Community. Journal of Scientific Research \& Reports, 11(3): 1-17, doi: 10.9734/JSRR/2016/26194

Semenza, J.C., Sudre, B., Oni, T., Suk, J.E., and Giesecke, J. (2013) Linking Environmental Drivers to Infectious Diseases:The European Environment and Epidemiology Network PLOS Neglected Tropical Diseases 7(7): e2323

Sen, A. (2011). The idea of justice. Harvard University Press.

Shields, M. and Price, S. (2001) Exploring the Economic and Social Determinants of Psychological and Psychosocial Health. Discussion Paper 396, Institute for the Study of Labour, Bonn.

Shukla, J. (2013) Extreme Weather Events and Mental Health: Tackling the Psychosocial Challenge. ISRN Public Health Article ID 127365: 1-7, doi.org/10.1155/2013/127365

Smith, K R and Desai, M A. (2009). The contribution of global environmental factors to illhealth. In Martens, P and McMichael, A J (editors). Environmental Change, Climate and Health. Issues and research methods. Cambridge, Cambridge Universtity Press: 52-95

Souza Santos, B. (1993) Modernidade, identidade e a cultura de fronteira. Tempo Social; Rev. Sociol 5(1-2): 31-52.

Spinner-Halev, J. (2012) Enduring Injustice (Cambridge: Cambridge University Press.

Srivastava, K. (2009). Urbanization and mental health Int Psychiatry J. 18(2): 75-76 . doi: $10.4103 / 0972-6748.64028$

Stengers, I (2008) Experimenting with refrains: Subjectivity and the challenge of escaping Modern dualism. Subjectivity 22, 38-59. doi:10.1057/sub.2008.6 
Szerszynski, B. and Urry, J. (2010) Changing Climates: Introduction. Theory, Culture \& Society 27(2-3): 1-8, doi: 10.1177/0263276409362091

Tacoli, C. (2009) Crisis or adaptation? Migration and climate change in a context of high mobility. Environment and Urbanization 21: 513, doi: 10.1177/0956247809342182

Tafarodi, R. W. (2013) Introduction. In Tafarodi, R. W (editor). Subjectivity in the TwentyFirst Century: Psychological, Sociological and Political Perspectives. New York/USA: Cambridge University Press, 1-8.

Terkelsen, T. (2009) Transforming subjectivities in psychiatric care. Subjectivity 27 (1): 195216. doi:10.1057/sub.2009.6

The Lancet. Editorial (2016). What can public health do for mental health? The Lancet, 387 June 25: 2576.

Thomas, M J (2013). Public and Expert Perceptions of Sea-level Change on the Severn Estuary. $\mathrm{PhD}$, thesis, Cardiff University/UK

Thornicroft, G and Votruba, N. (2016). Does the United Nations care about mental health? The Lancet, 3: $599-600$.

Thrift, N. (2008) I just don't know what got into me: where is the subject? Subjectivity 22: 82-89, doi:10.1057/sub.2008.1

Turner II, B.L., Kasperson, R. E, Meyer, W. B, Dow, K. M, Golding, D, Kasperson, J. X, Mitchell, R. C, and Ratick, S. J. (1990) Two types of global environmental change Definitional and spatial-scale issues in their human dimensions. Global Environmental Change, $14-22$.

Walkerdine, V. (1985) On the regulation of speaking and silence: Subjectivity, class and gender in contemporary schooling. In: C. Steedman; C. Unwin and V. Walkerdine (Eds.). Language, gender and childhood. Londres, Boston e Henley, Routledge \& Kegan Paul 1985: 203-241.

Walkerdine, V. (2007). Ciência, Razão e a Mente Feminina. Educação \& Realidade, 32(1): 7-24, jan/jun

Weber, M. (1946) Science as a Vocation. Gerth, H. H and Wright Mills, C (Translated and edited). From Max Weber: Essays in Sociology 129-156

Weber, M. (1958) The protestant ethic and the spirit of capitalism. Trad. T. Parsons. New York: Scribners.

Weintrobe, S. (2013) Engaging with Climate Change: Psychoanalytic and Interdisciplinary Perspectives (New Library of Psychoanalysis 'Beyond the Couch' series). UK:

Routledge[ss11]

Weisler, R.H., Barbee, J.G. and Townsend, M.H. (2006) Mental Health and Recovery in the Gulf Coast After Hurricanes Katrina and Rita. JAMA 296(5):585-588, doi:10.1001/jama.296.5.585.

Wetherell, M. (2008) Subjectivity or psychodiscursive practices? Investigating complex Intersectional identities. Subjectivity 22: 73-81, doi:10.1057/sub.2008.7

Whitmarsh, L (2009). Behavioural responses to climate change: Asymmetry of intentions and impacts. Journal of Environmental Psychology, 29 (1):13-23, doi:10.1016/j.jenvp.2008.05.003 
Wolf, T. and McGregor, G. (2013) The Development of a Heat Wave Vulnerability Index for London, United Kingdom, Weather and Climate Extremes 1: 59-68, doi.org/10.1016/j.wace.2013.07.004

Yamana, T.K. and Eltahir, E.A. (2013) Projected impacts of climate change on environmental suitability for malaria transmission in West Africa. Environ Health Perspect 121:1179-1186, doi.org/10.1289/ehp.1206174

Zimmerman, R. and Faris, C. (2011) Climate change mitigation and adaptation in North American cities. Current Opinion in Environmental Sustainability 3:181-187. doi 10.1016/j.cosust.2010.12.004 